\title{
Smartphone application: useful tool in hand hygiene adherence control
}

\author{
Eduardo Signor Basso ${ }^{1}$, Barbara Spall ${ }^{1}$, Eduarda Stopiglia Roth ${ }^{1}$, \\ Eliane Carlosso Krummenauer ${ }^{2,3}$, Rochele Mosmann Menezes ${ }^{2,3}$, Janine Koepp ${ }^{4}$, \\ Janete Aparecida Alves Machado ${ }^{2}$, Cezane Priscila Reuter ${ }^{3,5}$, Marcelo Carneiro ${ }^{2,3,6}$
}

${ }^{1}$ Department of Biology and Pharmacy, Medicine School, University of Santa Cruz do Sul, Rio Grande do Sul, Brazil

${ }^{2}$ Hospital Infection Control Committee, Hospital Santa Cruz, Rio Grande do Sul, Brazil

${ }^{3}$ Strictu sensu Postgraduate Program in Health Promotion, University of Santa Cruz do Sul, Rio Grande do Sul, Brazil

${ }^{4}$ Nursing School, University of Santa Cruz do Sul

${ }^{5}$ Department of Biology and Pharmacy - Pharmacy School, University of Santa Cruz do Sul, Rio Grande do Sul, Brazil

${ }^{6}$ Professor of the Department of Biology and Pharmacy - Medicine School, University of Santa Cruz do Sul.

10.3396/ijic.v16i2.014.20

\begin{abstract}
This study analysed hand hygiene adherence based on the direct observation computed through a standardized electronic form (Google forms ${ }^{\circledR}$ ) available in a smartphone. The observed monthly adherence rates increased during the period. The frequency rates were $21.3 \%$ in September; $33.3 \%$ in October; $38.7 \%$ in November; and $59.7 \%$ in December $(p<0.001)$. The introduction of direct observation through a smartphone facilitated the strategies and provided periodic feedback.
\end{abstract}

Keywords: hand hygiene, compliance, behaviour, healthcare associated infection, intensive care unit, smartphone, Brazil

\section{Introduction}

Hand hygiene $(\mathrm{HH})$ is the most significant measure to prevent the cross-transmission (CT) of microorganisms, being an important component of patient safety. ${ }^{1}$ However, the lack of adherence by health professionals (HPs) is a dilemma identified worldwide, despite being a professional ethical responsibility. $^{2}$
In 2016 in Brazil, the Healthcare-Associated Infections (HAls) in an Adult Intensive Care Unit (ICU) showed an incidence density rate (50th percentile) of $3.3 / 1000$ patient-days in primary bloodstream infection associated with central venous catheter use; 3.9/1000 patient-days in urinary tract infections associated with long-term indwelling urinary catheters; and 12/1000 patient-days in

\section{Corresponding Author}

Marcelo Carneiro

Hospital Santa Cruz, Rua Fernando Abott, 174, CEP, Santa Cruz do Sul, Rio Grande do Sul, Brasil

E-mail:marceloc@unisc.br 
ventilator-associated pneumonia.3 To decrease these frequencies, the World Health Organization (WHO) $\mathrm{HH}$ guidelines established methods of measuring $\mathrm{HH}$ practice, basically through direct observation and alcohol quantification per hospital unit. ${ }^{4}$ Therefore, this study aimed to analyse the HH of HPs at the 5 moments recommended by the WHO in an ICU in the countryside of southern Brazil.

\section{Method}

A prospective, single-centre and noninterventional study was developed by the Hospital Infection Control Committee (HICC) team of a teaching hospital located in southern Brazil, in an adult ICU (clinical and surgical) with 10 beds. The observations were carried out from September to December 2018, 3 times a week, in the morning, afternoon and evening shifts, as part of the routine epidemiological surveillance of HICC.

The $5 \mathrm{HH}$ moments that synthesize the indications for the HPs in cases in which $\mathrm{HH}$ is mandatory were used: Moment 1 (M1): "before contact with the patient", Moment 2 (M2): "Before the aseptic procedure performance", Moment 3 (M3): "After the risk of exposure to body fluids", Moment 4 M4): "After contact with the patient"; and Moment 5 (M5): "After contact with areas close to the patient."

Data collection was computed using an electronic standardized form (Google forms $\left.{ }^{\circledR}\right),{ }^{5}$ through which observers, when arriving at the ICU, waited for the first opportunity for the direct observation of care identifying which HP category it was. Thus, they maintained the observation until the end of patient care, filling out a form to verify $\mathrm{HH}$ adherence. All the results were monthly sent to the heads of the unit by e-mail and, thus, the results were disseminated in monthly meetings with the staff.

To quantify the amount of alcohol used in the $\mathrm{HH}$ process, the indicator was used in millilitres of alcohol/patient-days/ICU unit and, thus, the monthly quantification could be estimated, since the section has a known stock of the product.

The study outcome was the overall prevalence of $\mathrm{HH}$ adherence and adherence at each of the 5 moments. To calculate adherence, the number of opportunities for $\mathrm{HH}$ and those actually performed were assessed in person by the evaluator in the unit during the practices. The association of the professional category of the evaluated professional and the work shift were not assessed in relation to the adherence rates in this study.

Statistical analysis of the data was carried out using the SPSS $®$ Program, version 23.0 (Statistical Package for the Social Sciences, IBM, Armonk, NY, USA). Initially, the adherence versus non-adherence comparison was performed at each of the 5 moments, during the four months of data collection. An analysis was performed to verify the prevalence of outcomes and their association with the professional category (doctors, nurses, nursing technicians, others). The category "others" consisted of physical therapists, psychologists, dentists, nutritionists, pharmacists, and audiologists/speech therapists. The chi-square test was used in all statistical analyses, with the significance set at $p<0.05$.

The study was approved by the hospital's ethics committee.

\section{Results}

A total of 790 opportunities for $\mathrm{HH}$ were analysed. The overall $\mathrm{HH}$ adherence was $36.6 \%$. The adherence analysis at the isolated $\mathrm{HH}$ moments was: $\mathrm{M1}=$ $25.7 \% ; M 2=53.3 \% ; M 3=86.36 \% ; M 4=50 \%$; and, M5 $=68.84 \%$ (Figure 1).

Regarding the professional category, the opportunities for $\mathrm{HH}$ were: 323 (40.8\%) for nursing technicians, 112 (14.2\%) for nurses, 151 (19.1\%) for physicians and $134(17 \%)$ in the category "others". The $\mathrm{HH}$ adherence rate was $30.0 \%, 39.2 \%, 41.7 \%$ and $39.5 \%$ for nursing technicians, nurses, physicians and others, respectively. The analysis of the healthcare undergraduate students resulted in 70 opportunities (8.9\% of the total) and an adherence rate of $31.4 \%$. ( $P$ $=0.062$ ).

The amount of alcohol used was $24.3 \mathrm{~mL} /$ patient / day during the period.

\section{Discussion}

The overall rate of $\mathrm{HH}$ adherence found in this study was low, and lower when compared to two other 


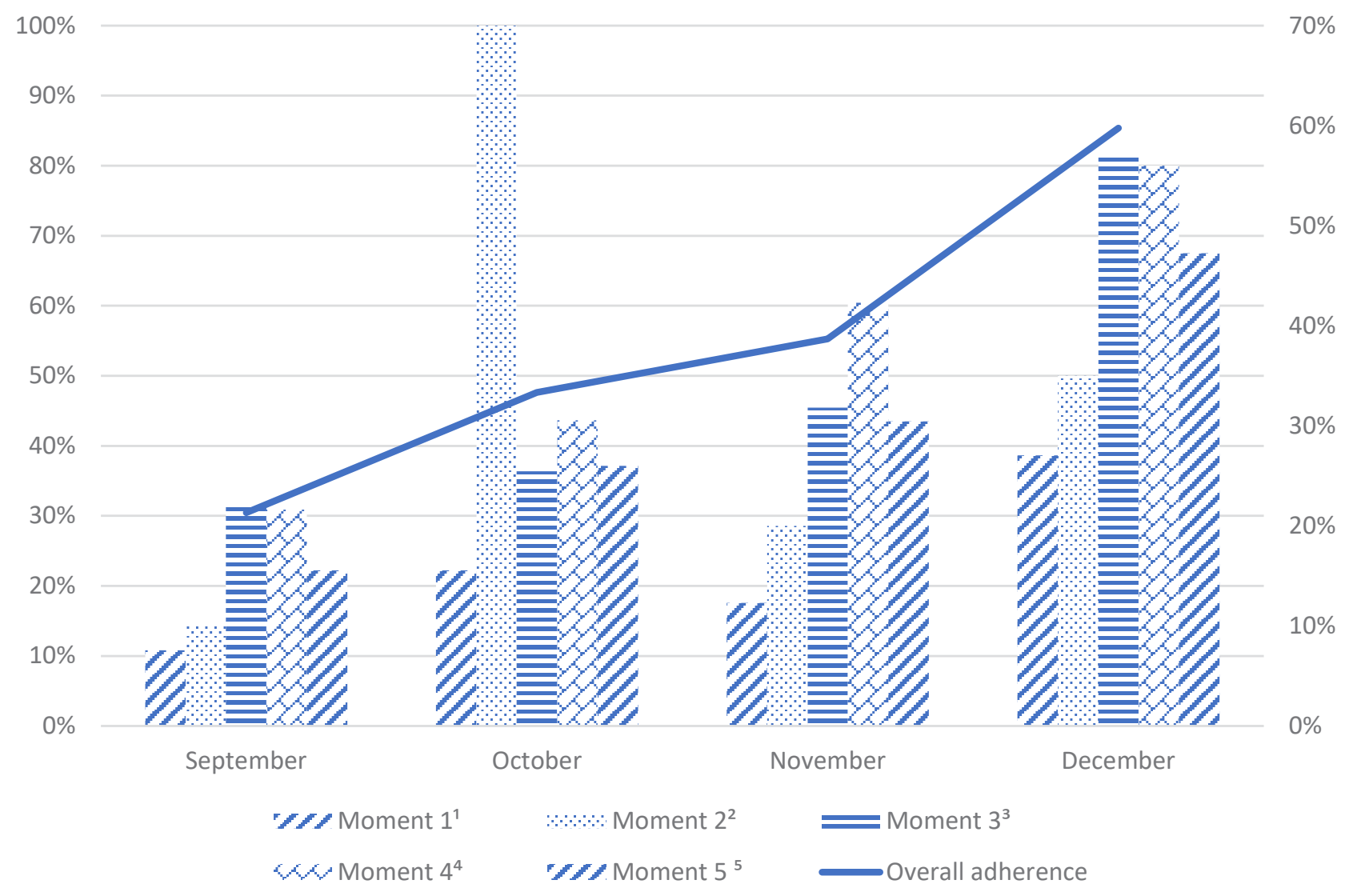

Figure 1. Adherence to hand hygiene by health professionals, from October to December 2018, at the Adult Intensive Care Unit, Hospital Santa Cruz, in the countryside of southern Brazil. Chi-square test: * $1(\mathrm{P}=0.003) ;{ }^{*} 2(\mathrm{P}=0.250) ;{ }^{*} 3(\mathrm{P}=0.014) ;{ }^{*} 4(\mathrm{P}<0.001) ;{ }^{*} 5(\mathrm{P}<0.001) ;{ }^{*}$ Overall adherence $(\mathrm{P}<0.001)$

studies, both performed in Kuwait, which found, respectively, adherence rates of $43 \%$ and $69.1 \% .6,7$ Regarding the $\mathrm{HH}$ moments, one can infer that the low adherence at $M 1$, when compared to $M 3, M 4$ and M5, reflects the concern of HP with self-care and neglect with patient safety. ${ }^{2}$ This situation is not justified, since there are no major structural obstacles for the effective performance of $\mathrm{HH}$ in the ICU. The availability and placement of the alcohol dispensers and the presence of posters in each bed, recalling the importance of $\mathrm{HH}$, were certified and all the HPs periodically participate in institutional training.

The prospective analysis from September to December of the monthly isolated $\mathrm{HH}$ adherence moments disclosed a significant increase in adherence rates at all moments, except for M2. This was due to the reduced number of opportunities, such as in October, which had a total of one opportunity. Possibly, an increase in sample size will solve this problem with such an indicator. However, the adherence rates at the other moments - especially the M4 and M5, which showed the highest significant increase - as well as the monthly overall adherence rates, confirm that the direct observation and periodic feedback are effective strategies in increasing $\mathrm{HP}$ involvement with $\mathrm{HH}^{8}$

The control of $\mathrm{HH}$ adherence through answers in an application installed in a smartphone work as a tool to facilitate the study and generate automatic data to send feedback - without the introduction of interventionist means, which has been well-demonstrated in other studies. ${ }^{6,9}$ This is characterized as a key strategy for developing countries that find it difficult to establish $\mathrm{HH}$ adherence, since the app is free, easy to operate and is a very useful tool for collecting data, which is then transformed into interventions that improve adherence.

When analysing the professional categories, there was no significant difference between the adherence rates. However, it is known that the adherence rates among the nursing staff are usually significantly higher than 
those found among the medical staff, and it may be due to the activity that offers more $\mathrm{HH}$ opportunities. ${ }^{7}$

This study also showed the $\mathrm{HH}$ adherence rates among healthcare undergraduate students, due to the fact that the hospital is directly linked to university-level education, which showed a low indicator, although similar to the HPs, such as the technical nursing staff. The quantification of alcohol consumption was adequate according to the WHO standardization. ${ }^{4}$

Finally, the observation of $\mathrm{HH}$ opportunities was characterized by a constant feeling of reaffirming the empathy values in the health services, so that the professionals can establish a positive habit based on their concern for the patient. Moreover, the previously undertaken actions should be immediately redirected and expanded, aiming to permanently transform behaviour and, thus, generate commitment within a network of positive attitudes, with increasingly higher adherence rates.

\section{References}

1. Mundy LM Contamination, acquisition, and transmission of pathogens: implications for research and practice of infection control. Infect Control Hosp Epidemiol 2008; 29(7): 590-592. https://doi.org/10.1086/589558

2. Carneiro M, Persch MS, Souza JG, Krummenauer EC, Machado JAA What is the distance between saying and doing? Int J Infect Control 2012; 8: i2. https://doi.org/10.3396/ ijic.v8i2.020.12

3. Agência Nacional de Vigilância Sanitária; Ministério da Saúde. Boletim Segurança do Paciente e Qualidade em Serviços de Saúde $n^{\circ} 16$ : Avaliação dos indicadores nacionais das Infecções Relacionadas à Assistência à Saúde (IRAS) e Resistência microbiana do ano de 2016. 2017. Brasil.

4. World Health Organization. WHO guidelines on hand hygiene in health care. Published 2009. World Health Organization website. Available from: http://apps.who.int/ iris/ bitstream/10665/44102/1/9789241597906_eng.pdf. (Accessed January 16, 2019).

5. Salama MF, Jamal WY, Al Moussa HA, Al-Abdulghani KA, Rotimi VO. The effect of hand hygiene compliance on hospitalacquired infections in an ICU setting in a Kuwaiti teaching hospital. J Infect Public Health 2013; 6(1): 27-34. https://doi. org/10.1016/j.jiph.2012.09.014

6. Ramadan M, Hamza W, Alfadhli M. Impact of an intervention on the hand hygiene compliance rates in paediatric surgical intensive care units in two tertiary care hospitals. Int J Infect Control, 2018; 14(2). https://doi.org/10.3396/IJIC. v14i2.008.18

7. Arise K, Nishizaki S, Morita T, Yagi Y, Takeuchi S. Continued direct observation and feedback of hand hygiene adherence can result in long-term improvement. Am J Infect Control 2016; 44(11): e211-e214. https://doi.org/10.1016/j. ajic.2016.07.011

8. Laskar AM, Deepashree R, Bhat P, et al. A multimodal intervention to improve hand hygiene compliance in a tertiary care center. Am J Infect Control 2018; 46(7): 775-780. https:// doi.org/10.1016/j.ajic.2017.12.017 